
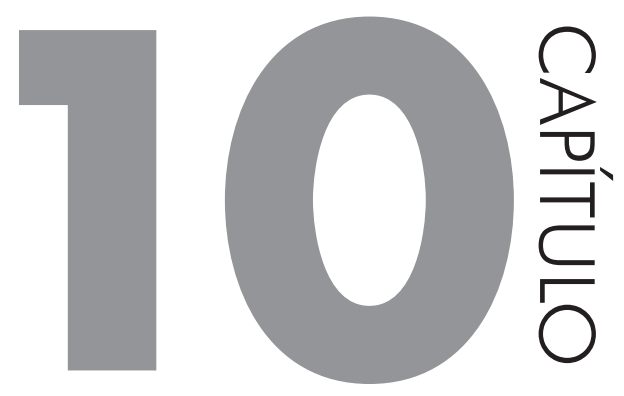

\title{
A LATERAL PALATAL NO PORTUGUÊS DO BRASIL E NO PORTUGUÊS EUROPEU: um estudo sociolinguístico comparativo
}

\section{VIVIAN DE OLIVEIRA QUANDT ${ }^{1}$}

\section{INTRODUÇÃO}

A concepção de língua como um sistema heterogêneo proposto pela Sociolinguística acarreta uma série de implicações, no âmbito das análises linguísticas, uma vez que a variação passa a ser, muitas vezes, o centro dos estudos no que se refere ao processo de estruturação da língua. (cf. LUCCHESI, 1998)

Sabendo-se que as línguas se modificam com o tempo e que essas mudanças não ocorrem abruptamente, mas sim de maneira gradual - em que se supõe um estágio de variação -, parece importante demonstrar não só o que acontece durante a implementação da mudança, mas também porque ela ocorre.

\footnotetext{
Silvia, agradeço-lhe pelos momentos em que de você pude receber tantos ensinamentos, não só acadêmicos. Desde a graduação, época em que a conheci, pude entender o que é ser um bom professor e, principalmente, comecei a aprender com você a fonética e a fonologia. Depois, durante a Iniciação Científica, mestrado e doutorado, você, além de guiar os meus passos no mundo acadêmico e científico, mostrou-me do quanto eu era capaz. Por tudo isso e muito mais, você é uma pessoa a quem admiro e procuro seguir.
} 
Nesse sentido, como ainda há muito a conhecer sobre o Português do Brasil (PB) e o Português Europeu (PE), procura-se caracterizar essas variedades, observando-se fenômenos variáveis e processos de grande relevância, como é o caso do que ocorre com os fonemas laterais que merecem atenção especial já que podem não só ocupar diversas posições no vocábulo, mas também apresentar significativa gama de variantes. A lateral [+ anterior] pode ser encontrada em posição inicial (lado, mala), medial - como segundo segmento de grupo consonântico) - (clara) e final de sílaba (calma, canal). A [- anterior] ocupa, fundamentalmente, a posição intervocálica (mulher, velha), sendo atestadas variantes oriundas da atuação de diferentes processos, entre os quais a iodização e a despalatalização.

O trabalho proposto tem como tema o comportamento da lateral palatal na fala culta e popular da Região Metropolitana do Rio de Janeiro (Municípios de Nova Iguaçu e do Rio de Janeiro, este representado por Copacabana) e da Região Metropolitana de Lisboa (Oeiras e Cacém) e foi desenvolvido à luz dos pressupostos da Teoria da Variação Laboviana, com base em dois corpora, tanto o que se refere ao $\mathrm{PB}$, quanto o que diz respeito ao $\mathrm{PE}$, eliciados de entrevistas que constituem o Acervo do Projeto Estudo comparado dos padrões de concordância em variedades africanas, brasileiras e europeias do Português (www.letras.ufrj.br/ concordancia).

A lateral palatal é um tema polêmico do ponto de vista tanto fonológico quanto fonético. Como se sabe, ela constitui um dos quatro fonemas do Português moderno ${ }^{2}$ não existentes em latim e resultantes de processo de palatalização. O processo que lhe deu origem consolidou-se, a depender dos contextos fônicos, em diferentes estágios da evolução do latim ao Português e que recobrem o período que vai do século IV ao XV-XVI.

A lateral palatal deriva-se basicamente do contexto fônico - $l j$, resultante (a) da transformação em semivogal de vogal [+ant] subsequente à lateral anterior, como em fi.li.u > fi.ljo > filho; (b) da vocalização da consoante velar no grupo - $c l$ - (originalmente $-c l$ - ou $<-t l$-), medial de vocábulo e precedido de vogal, com posterior passagem a semivogal e metátese, como em oculu $>$ oclu $>$ "ojlo $>$ "oljo $>$ olho; vetulu $>$ vetlu $>$ veclu $>$ "vejlo $>$ "veljo > velho; (c) e também dos grupos mediais latinos - $g l$ - e $-b l$, como em trib(u)lu $>$ trilho; teg $(\mathrm{u}) l \mathrm{la}>$ telha.

Estudos sobre o Português do Brasil, sobretudo em referência à variedade popular, em comunidades rurais, têm mostrado a frequência da "vocalização" (iodização) e da "simplificação" (despalatalização) da lateral palatal, citando-se, respectivamente, como exemplos, [mu’je] e [mu'le], em lugar de mu[K]er.

2 Os três outros são $/ \mathrm{J} /, / 3 /, / \mathrm{n} /$. 
Segundo Brandão (2006, p. 67-68), na fala espontânea, o contraste /li/ x / $/$ fica comprometido e, frequentemente, não é efetivado o que torna pares de vocábulos como Júlio e julho, por exemplo, homófonos, ambos realizando-se ora como ['zulju], ora como ['3uKu]. Isso, ainda de acordo com a autora, "é corroborado por outros vocábulos, como família, frequentemente concretizado como fami[ $K]$ a”.

Como o Estado do Rio de Janeiro carece de mais estudos a respeito do uso da lateral palatal, que possam contemplar não apenas a variedade popular, mas também a culta e como são muito escassos os trabalhos sobre o uso de / $/$ / no PE, torna-se pertinente, portanto, verificar se (a) uma das variantes constitui norma de pronúncia em diferentes áreas da Região Metropolitana do Rio de Janeiro e da Região Metropolitana de Lisboa e (b) se as diferentes formas de concretização de $[\Lambda]$ são condicionadas por fatores linguísticos e/ou extralinguísticos.

\section{METODOLOGIA E CORPUS}

Os dados que constituem os corpora da pesquisa foram selecionados de inquéritos, do tipo DID, pertencentes ao Acervo do projeto Estudo comparado dos padrões de concordância em variedades africanas, brasileiras e europeias do Português (www.letras.ufrj.br/concordancia).

Os inquéritos foram realizados com indivíduos distribuídos pela Região Metropolitana do Rio de Janeiro (RMRJ) e pela Região Metropolitana de Lisboa (RMLIS), por sexo, três níveis de instrução $\left(2^{\circ}\right.$ segmento do Ensino Fundamental, Ensino Médio e Ensino Superior) e três faixas etárias - A (18-35 anos), B (36-55 anos), C (56-70 anos).

No que diz respeito ao corpus do PB, o estudo foi feito com base na fala dos Municípios de Nova Iguaçu e do Rio de Janeiro, mais especificamente do bairro de Copacabana, o que perfez um total de 36 informantes. Com relação ao corpus do PE, o trabalho foi realizado com base na fala de Oeiras, localizada em Lisboa, e da freguesia de Cacém, somando, também, um total de 36 informantes.

As variáveis dependentes e independentes utilizadas no estudo foram as mesmas tanto na análise efetuada com dados da RMRJ, quanto na empreendida com os da RMLIS. O mesmo se verificou no que diz respeito à variável dependente: durante as transcrições fonéticas, observou-se que as variantes de $/ \mathcal{K} /$ eram as mesmas no PB e no PE, havendo apenas uma diferença percentual de ocorrência em cada uma das variedades estudadas.

Entre as variáveis estruturais, inicialmente, controlaram-se os contextos antecedente e subsequente; a classe de vocábulo; a tonicidade da sílaba em que incide o segmento, o número de sílabas do vocábulo, a presença ou ausência de outra líquida palatal no vocábulo e a frequência do vocábulo no corpus. 
Da análise auditiva dos dados, registraram-se as seguintes variantes de $/ K /$, cuja distribuição, nos corpora, se encontra nas tabelas 1 e 2 e pode, também, ser visualizada nos gráficos 1 e 2 .

- Lateral palatalizada [i]

Três professoras super-maravi[ $\mathbf{l}^{\mathrm{i}}$ ]osas (COP A1M)

que possa beneficiar o seu traba[ $\mathrm{l}^{\mathrm{j}}$ ]o $(\mathrm{CAC} \mathrm{C} 3 \mathrm{H})$

- Manutenção da palatal [ $\Lambda]$

então ele traba[ $\mathrm{\Lambda}]$ a em casa $(\mathrm{COP} \mathrm{C} 2 \mathrm{M})$

acho que quero ter $f i[\Lambda]$ os $(\mathrm{CAC} \mathrm{A} 1 \mathrm{H})$

- Despalatalização seguida de semivogal $\mathrm{j}[\mathrm{lj}]$

e os fi $\mathrm{l} \mathrm{l}$ ] los do seu Manoel também (COP B1M)

era o meu fi $[\mathrm{lj}]$ o (CAC B1M)

- Iodização [j]

eu ficava mais perto do traba $\mathbf{j}$ ]o (COP C1 H)

o[ $\mathbf{j}] a$ é o que eu disse à bocadinho (CAC B2M)

- Despalatalização [1]

a minha mu[1]er (COP C1 H)

todos os traba[ 1 ]inhos feitos (CAC B2M)

- Síncope do segmento [Ø]

eles andava minha fi $\varnothing \mathrm{l} a(\mathrm{COP} \mathrm{C} 1 \mathrm{H})$

vai ficar $f i[\varnothing] a(\mathrm{OEI} C 3 \mathrm{M})$

\section{ANÁLISE SOCIOLINGUÍSTICA COMPARATIVA ENTRE A RMRJ E A RMLIS}

Este estudo, por ser um recorte de um trabalho feito anteriormente (cf. QUANDT, 2014), apresentará apenas as variáveis em comum que foram selecionadas, tanto na RMRJ quanto na RMLIS, como favorecedoras da aplicação da lateral palatalizada.

Antes, porém, de serem apresentados os resultados das análises probabilísticas efetuadas, mostra-se pertinente demonstrar como as variantes de / $\mathrm{K} /$ se distribuíram em ambas as regiões investigadas.

\subsection{As variantes de / / / no corpus do PB e no corpus do PE}

Conforme se demonstra na Tabela 1 e no Gráfico 1, a seguir, na RMRJ, a lateral palatalizada, com índice de frequência de 55.2\% (1363 ocorrências), surge 
como a variante preferencial em contraste com a manutenção da lateral palatal, que atinge o índice de $28.6 \%$ (705 ocorrências). As demais variantes apresentam baixa representatividade na amostra, a saber: despalatalização + iode ([li]]) - 13\%; despalatalização $([1])-2.6 \%$; iodização $([j])-0.5 \%$ e síncope $(\varnothing)-0.1 \%$.

Tabela 1 Índices referentes à variação de /א/ na RMRJ.

\begin{tabular}{|c|c|c|c|c|c|c|}
\hline ÍNDICES & \multicolumn{7}{|c|}{ VARIAÇÃo DE /K/ NA RMRJ } \\
\hline VARIANTES & {$[$ [l] } & {$[\mathcal{K}]$} & {$[\mathbf{l j}]$} & {$[\mathrm{l}]$} & {$[j]$} & $\varnothing$ \\
\hline Ocorrências & $1363 / 2470$ & $705 / 2470$ & $323 / 2470$ & $64 / 2470$ & $13 / 2470$ & $2 / 2470$ \\
\hline Percentuais & $55.2 \%$ & $28.6 \%$ & $13 \%$ & $2.6 \%$ & $0.5 \%$ & $0.1 \%$ \\
\hline
\end{tabular}

$56 \%$

$29 \%$

$13 \%$

$2 \%$

\section{$0 \% \square 0 \%$}

Lateral palatalizada

Manutenção da

Palatal

Despalatalização + lode

Despalatalização

Gráfico 1 Distribuição das variantes de /K/ na RMRJ.

Os baixos índices de algumas variantes, de certa maneira, já eram esperados, uma vez que esse corpus representa a fala de Copacabana - bairro localizado na Zona Sul da cidade do Rio de Janeiro - e de Nova Iguaçu - cidade que apresenta um dinâmico polo comercial, cuja população mantém uma permanente interação com os moradores da capital. A iodização, por exemplo, é considerada típica do interior ou de zonas rurais do Brasil, como atestam não só trabalhos mais antigos como os de Penha (1972), Melo (1981), Silveira (1986) e Aguilera (1988), mas também estudos mais recentes, como o de Brandão (2006). Também o cancelamento e a despalatalização da lateral palatal são vistos como característicos da fala rural e interiorana em três dos estudos apontados anteriormente: Penha (1972), Aguilera (1988) e Brandão (2006).

O fato de a lateral palatalizada ser a variante mais utilizada nessas localidades não surpreende, uma vez que muitos linguistas como Pontes (1973) e Cristófaro-Silva (1999), por exemplo, indicam ser [li] a variante preferida dos brasileiros. 
A primeira afirma, inclusive, que não existe, na língua coloquial, o contraste que é sugerido pela escrita, como em óleo-olho, que se pronunciariam da mesma maneira: [ol'u]. Já a segunda assevera que, geralmente, a lateral alveolar palatalizada ocorreria no lugar da lateral palatal na fala da maioria dos falantes do Português brasileiro.

Como pode ser verificado na Tabela 2 e no gráfico 2, na RMLIS, a lateral palatalizada, com índice de frequência de 54.1\% (941 ocorrências), também aparece como a variante preferencial em contraste com a manutenção da lateral palatal, que atinge o índice de $37.6 \%$ (653 ocorrências). As demais variantes, como no $\mathrm{PB}$, apresentam baixa representatividade, a saber: despalatalização + iode ([li]]) $-6.2 \%$; despalatalização $([1])-1 \%$; iodização $([j])-1 \%$ e síncope $(\varnothing)-0.1 \%$.

Tabela 2 Índices referentes à variação de /K/ na RMLIS.

\begin{tabular}{|c|c|c|c|c|c|c|}
\hline IINDICES & \multicolumn{6}{|c|}{ VARIAÇÃO DE /K/ NA RMLIS } \\
\hline VARIANTES & [li] & {$[\kappa]$} & [lj] & [I] & [j] & $\varnothing$ \\
\hline Ocorrências & $941 / 1739$ & $653 / 1739$ & $107 / 1739$ & 20/1739 & 17/1739 & $1 / 1739$ \\
\hline Percentuais & $54.1 \%$ & $37.6 \%$ & $6.2 \%$ & $1.2 \%$ & $1 \%$ & $0.1 \%$ \\
\hline
\end{tabular}

\section{$54 \%$}

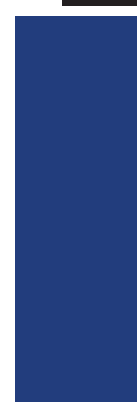

\section{$38 \%$}

Lateral palatalizada

Manutenção da

Palatal

Despalatalização + lode

Despalatalização

Gráfico 2 Distribuição das variantes de /א/ na RMLIS.

Comparando os resultados percentuais obtidos nos dois corpora, percebe-se que, embora os índices da lateral palatalizada sejam bem próximos no $\mathrm{PB}$ e no $\mathrm{PE}$ (55.4\% e $54.1 \%$, respectivamente), a manutenção da lateral palatal ocorre com mais frequência no PE (37.6\% frente aos $28.5 \%$ do PB). Com exceção da vocalização $(\mathrm{PB}-0.5 \%$ - e $\mathrm{PE}-1 \%$ ), as demais variantes de $/ \mathrm{K} /$ foram menos produtivas no PE. (cf. tabelas 1 e 2 )

Um índice percentual de ocorrência da manutenção de / $/ /$ maior para o PE do que para o PB já era esperado. Embora não tenham sido encontrados estudos 
variacionistas sobre o comportamento da lateral palatal no PE, no momento da recolha dos dados, já era possível perceber que o número de ocorrências de $[\Lambda]$, nas localidades portuguesas estudadas, era maior do que o encontrado nas do Brasil. Ademais, o fato de a lateral palatalizada ser a variante mais encontrada no corpus do PE, também não surpreende, uma vez que, além de essa variante ser a preferida no PB (como atestam PONTES, 1973 e CRISTÓFARO-SILVA, 1999) ela também é, de alguma maneira, mencionada em estudos que caracterizam articulatoriamente o fonema $/ \mathcal{K} /$, não só no espanhol europeu, como também no PE (cf. QUILIS; FERNÁNDEZ, 1969; MARTINS et alii, 2008; MARTINS et alii, 2010).

Os baixos índices de algumas variantes apresentados na Tabela 2, de certa maneira, também já eram esperados. Assim como foi dito anteriormente, ainda que não tenham sido encontrados trabalhos que descrevessem a variação de $/ \mathcal{K} /$, no Português Europeu, esperava-se que, à semelhança do que ocorre no Português do Brasil, a iodização, a despalatalização e a síncope da lateral palatal não fossem comuns nas regiões ora analisadas, visto que nenhuma das duas é considerada interiorana ou rural: Oeiras é atualmente o município/concelho que apresenta um dos mais elevados índices de qualidade de vida de Portugal e Cacém é uma das maiores freguesias de Agualva-Cacém que, embora ainda seja considerada uma cidade-dormitório, é a quinta maior cidade da área metropolitana de Lisboa e a décima maior de Portugal.

Ainda no que se relaciona à vocalização da lateral palatal, vale acrescentar uma informação importante encontrada no estudo de Madureira (1999). Segundo ela, o Português falado em Portugal é a única língua latina que não registra, em momento algum de sua história, uma transformação da lateral palatal para a semivogal palatal. Esse dado é bastante curioso, não só porque a vocalização aparece no corpus do PE ora analisado, mas principalmente, porque ocorre num índice percentual mais alto do que o encontrado no corpus do PB (cf. tabelas 1 e 2).

\subsection{Variação /K/ / / / na RMRJ e na RMLIS}

Conforme pode ser verificado nas tabelas 1 e 2 e, também, nos gráficos 1 e 2, apresentados na seção anterior - em que se expõem os índices numéricos e percentuais de cada uma das variantes de $/ \mathcal{K} /$ encontradas em ambos os corpora -, devido à baixa produtividade de [lj], [1], [j] e $\varnothing$, a análise variacionista que será apresentada nesta seção só pôde ser realizada com as variantes manutenção da lateral palatal $([\Lambda])$ e lateral palatalizada $\left(\left[\mathrm{li}^{\mathrm{i}}\right]\right)$.

Como os dados relativos às variantes com baixa produtividade na amostra (despalatalização + iode ([lj]); despalatalização ([1]); iodização ([j]) e síncope (Ø) foram retirados dos corpora, as análises aqui empreendidas foram feitas com base nos índices expostos na Tabela 3. 
Tabela 3 Índices referentes à variação entre [li] vs [K] no PB e no PE.

\begin{tabular}{|c|c|c|c|c|}
\hline ÍNDICES & \multicolumn{2}{|c|}{ VARIAÇÃO ENTRE [L'] VS[K] NO PB } & \multicolumn{2}{|c|}{ VARIAÇÃO ENTRE [L'] VS[K] NO PE } \\
\hline VARIANTES & [li] & {$[\kappa]$} & [li] & {$[\kappa]$} \\
\hline Ocorrências & $1363 / 2068$ & $705 / 2068$ & $941 / 1594$ & $653 / 1594$ \\
\hline Percentuais & $65.9 \%$ & $34.1 \%$ & $59 \%$ & $41 \%$ \\
\hline
\end{tabular}

Logo numa primeira observação da Tabela 3, percebe-se que tanto no PB quanto no PE, a lateral palatalizada está se mostrando a variante preferida, uma vez que está ocorrendo com maior frequência do que $[\Lambda]$. Nota-se, ainda que, quando se comparam os índices percentuais de [li] no Brasil e em Portugal, vê-se que a lateral palatalizada é um pouco menos frequente no PE do que no PB: 59\% vs $65.9 \%$, respectivamente.

Além disso, cabe salientar que, com base na Tabela 3, verifica-se que a teoria defendida por Pontes (1973) parece não proceder, nas amostras aqui consideradas. Essa linguista elimina do quadro de fonemas a lateral palatal, afirmando não existir $[\mathcal{K}]$ no Português coloquial. Segundo ela, a lateral palatal pode ser interpretada como uma sequência $/ \mathrm{lj} /$. Embora com índice percentual mais baixo, $[\Lambda]$ aparece não só na fala do $\mathrm{PB}$, como também do PE. O que está ocorrendo, na verdade, é que, em ambas as variedades, coexiste, ao lado de $[\Lambda]$, uma outra variante, a lateral palatalizada $\left[{ }^{\mathrm{i}}\right]$, muito parecida com a lateral palatal, tanto articulatória quanto acusticamente.

A partir do momento em que se desconsideraram as demais variantes de $/ \mathcal{K} /$, foram realizadas diversas rodadas com o auxílio do Pacote de Programas GoldVarb-X, com o intuito de se verificar quais seriam as variáveis condicionadoras da variante palatalizada nas regiões ora estudadas.

Em todas as rodadas efetuadas, Faixa Etária e Classe do Vocábulo foram as variáveis selecionadas, em comum, tanto na RMRJ quanto na RMLIS, como favorecedoras da aplicação da lateral palatalizada. Nesse sentido, resolveu-se expor os resultados de ambas as variáveis em conjunto a fim de comparar o comportamento das duas variáveis nas regiões em foco.

\section{Faixa Etária}

Pelos resultados expostos na Tabela 4 , a variação $[\mathcal{K}] \sim[\mathrm{l}]$ parece ser um fenômeno estável na RMRJ, uma vez que os índices de ocorrência de [li] estão dis- 
tribuídos de forma homogênea pelas três faixas etárias - A (P. R. 0.577); B (P. R. 0.510) e C (P. R. 0.460). O mesmo está ocorrendo, na RMLIS. Ou seja, a Tabela 4 mostra que, assim como acontece na RMRJ, os indivíduos mais jovens e os de meia idade são os que estão preferindo a variante [li] na RMLIS: (Faixa A - P. R. 0.619; Faixa B - 0.557 e Faixa C - 0.335).

Tabela 4 Atuação da Variável Faixa Etária para a realização da variante palatalizada na RMRJ e na RMLIS.

\begin{tabular}{|c|c|c|c|c|c|c|c|}
\hline \multicolumn{8}{|c|}{ FAIXA ETÁRIA } \\
\hline \multicolumn{4}{|c|}{ RMRJ } & \multicolumn{4}{|c|}{ RMLIS } \\
\hline FATORES & OCO & $\%$ & P. R. & FATORES & OCO & $\%$ & P. R. \\
\hline $\begin{array}{l}\text { Faixa } A \\
\text { (18 - } 35 \text { anos) }\end{array}$ & $319 / 443$ & $72 \%$ & 0.577 & $\begin{array}{l}\text { Faixa } A \\
\text { (18 - } 35 \text { anos) }\end{array}$ & $331 / 487$ & $68 \%$ & 0.619 \\
\hline $\begin{array}{l}\text { Faixa B } \\
\text { (36 - } 55 \text { anos) }\end{array}$ & $551 / 809$ & $68.1 \%$ & 0.510 & $\begin{array}{l}\text { Faixa B } \\
\text { (36- } 55 \text { anos) }\end{array}$ & $361 / 553$ & $65.3 \%$ & 0.557 \\
\hline $\begin{array}{l}\text { Faixa } C \\
(56-70 \text { anos) }\end{array}$ & 498/821 & $60.7 \%$ & 0.460 & $\begin{array}{l}\text { Faixa } C \\
\text { (56- } 70 \text { anos) }\end{array}$ & $249 / 554$ & $44.9 \%$ & 0.335 \\
\hline
\end{tabular}

Os gráficos 3 e 4 mostram, com mais clareza, que, embora os resultados estejam bem parecidos nas duas Regiões Metropolitanas, na RMRJ, os dados de [i] parecem estar distribuídos de forma mais homogênea, visto que todas as faixas etárias apresentam P. Rs. próximos a .50. Já na RMLIS, tanto a faixa A, quanto a faixa $\mathrm{C}$, se distanciam um pouco mais da neutralidade: a primeira, apresentando P. R. 0.619, é a que mais favorece a aplicação da regra, e a segunda, com P. R. 0.335, a que menos se mostra propícia a implementar [li].

Esses resultados demonstram que, embora, na RMRJ, os P. Rs. estejam próximos de .50, são os mais velhos os que mais usam $[K]$ e os mais novos os que mais implementam [li], o que sugere, de forma bastante sutil, uma tendência crescente ao uso desta última variante no PB. Já no PE, o fato de o uso da variante palatalizada estar mais acentuado na fala dos mais jovens e menos na dos mais velhos, indica que a tendência ao uso de [li] está mais avançado. Em outras palavras: enquanto ainda é sutil o crescente uso de [li] no $\mathrm{PB}$, o mesmo não se pode dizer do que está acontecendo no PE (cf. gráficos 3 e 4). 


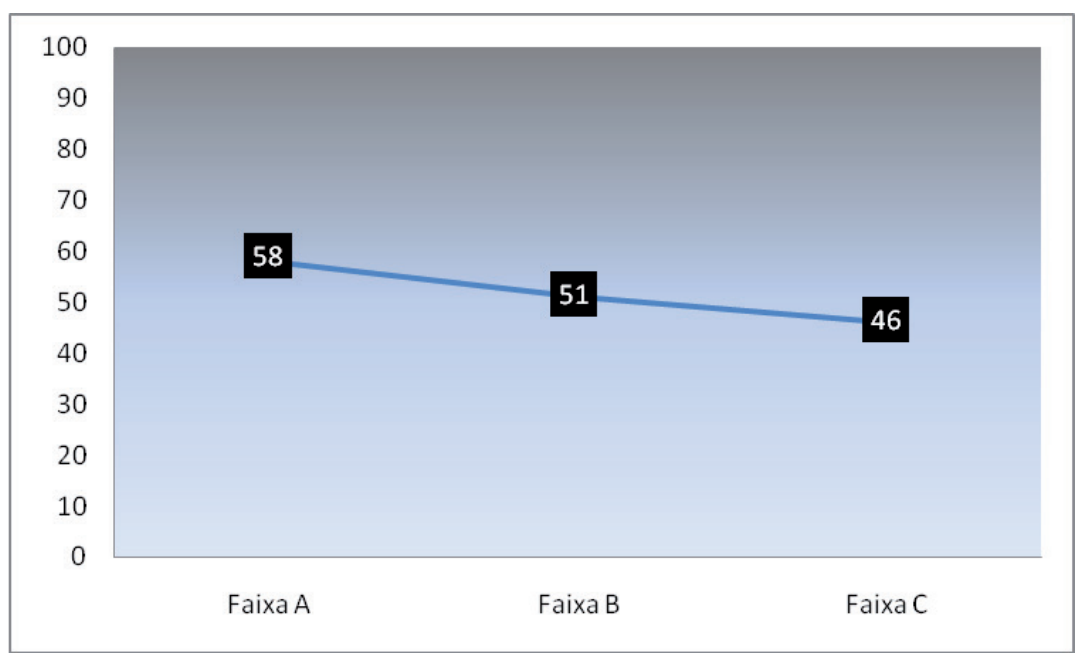

Gráfico 3 Atuação da Variável Faixa Etária para a realização da variante [li], no PB, em pesos relativos.

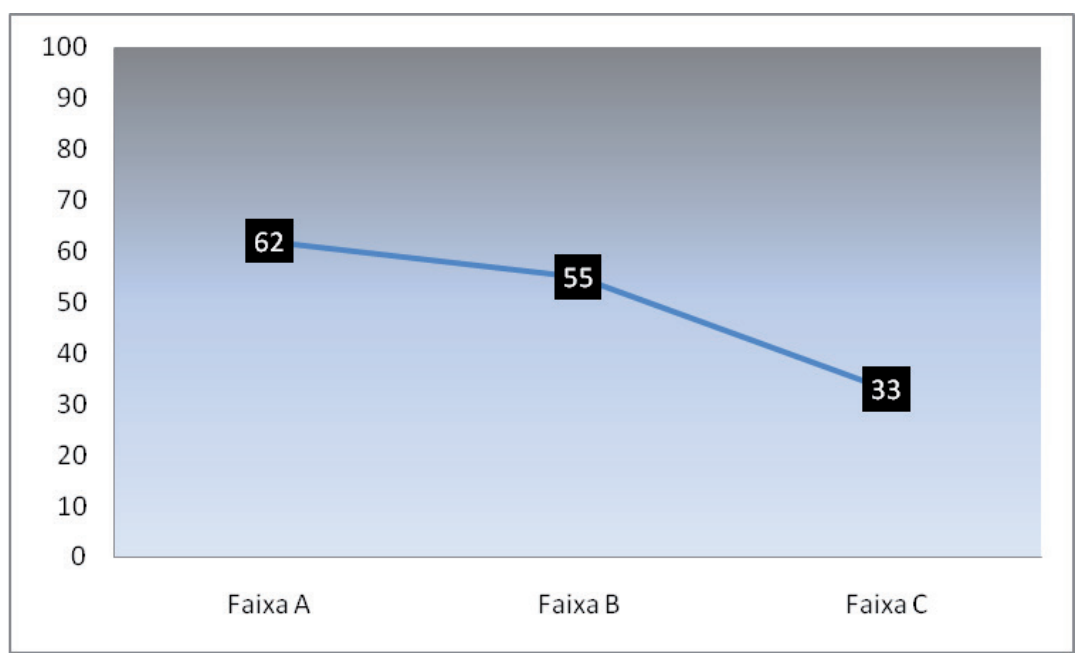

Gráfico 4 Atuação da Variável Faixa Etária para a realização da variante [li], no PE, em pesos relativos.

O resultado vai ao encontro do que é defendido por Labov (1972), para quem os mais velhos tendem a preservar as formas antigas, registradas na memória desde quando eram jovens. Naro (1992) concorda com Labov e, ainda, acrescenta que o processo de aquisição da linguagem se encerra no começo da puberdade, ficando, a partir desse momento, a língua do indivíduo praticamente estável. Assim, uma vez que $[\Lambda]$ é a variante conservadora, nada mais natural que ela esteja mais presente na fala dos mais velhos e [li], variante inovadora, na fala dos mais jovens. 


\section{(b) Classe do vocábulo}

Antes de comentar os índices referentes a esse grupo, cabe descrever as alterações realizadas nessa variável no decurso das análises efetuadas.

Logo de início, nas rodadas referentes à RMRJ, percebeu-se que Numeral e Pronome, por exemplo, deveriam ser retirados da análise, pois, além de apresentarem baixo número de ocorrências, neles a variante $[\mathcal{\Lambda}]$ era praticamente categórica: nos numerais ocorria em 11 dos 12 dados; entre os pronomes, em 4 dos 6 dados. Feito isso, ainda assim, após a realização de outras rodadas, verificou-se que seria necessário agrupar outros fatores, uma vez que estava havendo inversões nos resultados: classes de palavras que eram selecionadas como favorecedoras da aplicação da regra eram as que apresentavam índices percentuais mais baixos. Nesse sentido, resolveu-se unir os nomes (substantivo e adjetivo) confrontando-os aos verbos. A variável ficou reduzida a dois fatores: verbos e não verbos.

A modificação, no que diz respeito ao corpus do PE, foi um pouco diferente da efetuada com o do PB. Num primeiro momento, resolveu-se não desconsiderar qualquer fator. Depois, com base nos resultados, decidiu-se amalgamar os não verbos num único fator (substantivo, adjetivo, pronome, numeral) e contrastá-los aos verbos, deles separando-se "calhar", expressão muito produtiva na amostra. Ainda assim, os resultados não eram satisfatórios, uma vez que essa variável era selecionada como favorecedora de [li] e, ao mesmo tempo, era descartada. Em vista desses resultados, foi, então, necessário retirar da análise o fator numeral, visto que, pelo fato de ser pouco produtivo na amostra ( 8 ocos.) e ocorrer preferencialmente com $[\Lambda]$ (5 ocos.), poderia estar enviesando o resultado. Dessa forma, essa variável ficou formada por três fatores, a saber: verbo, não verbo (constituído por substantivo, adjetivo, pronome) e expressão "se calhar". Vale a pena mencionar, ainda, que, na tentativa de se formar um grupo binário, assim como ocorreu com o $\mathrm{PB}$, decidiu-se retirar da análise a expressão "se calhar" - para depois, analisá-la em separado, em função da sua grande produtividade com [li]. Essa tentativa, no entanto, não foi adequada, uma vez que, novamente, essa variável passou a ser selecionada e descartada. Em vista disso, decidiu-se manter o grupo com três fatores.

Conforme pode ser visto, na Tabela 5, no PB, são os verbos, com P. R. 0.636, os que mais influenciam a ocorrência da lateral palatalizada. Os não verbos (substantivos e adjetivos), com P. R. bem menor (0.396), parecem não estar favorecendo a aplicação de [li].

No PE, os verbos, também, mostram-se produtivos para a aplicação da regra (P. R. 0.516). A expressão "se calhar", no entanto, é a que mais está favorecendo a concretização de [li] - P. R. 702. Os não verbos, assim como aconteceu no PB, não favorecem a lateral palatalizada. 
Tabela 5 Atuação da Variável Classe do Vocábulo para a realização da variante [lij] na RMRJ e na RMLIS.

\begin{tabular}{|l|c|c|c|c|c|c|c|}
\hline \multicolumn{7}{|c|}{ CLASSE DO VOCÁBULO } \\
\hline \multicolumn{3}{|c|}{ RMRJ } & \multicolumn{3}{|c|}{ RMLIS } \\
\hline \multicolumn{1}{|c|}{ FATORES } & 0.0 & $\%$ & P. R. & FATORES & OCo & $\%$ & P. R. \\
\hline Verbo & $663 / 886$ & $74.8 \%$ & 0.636 & Verbo & $287 / 431$ & $66.6 \%$ & 0.516 \\
\hline $\begin{array}{l}\text { Não verbo } \\
\text { (Substantivo } \\
\text { e adjetivo) }\end{array}$ & $703 / 1169$ & $60.1 \%$ & 0.396 & $\begin{array}{l}\text { Não verbo } \\
\text { (Substantivo, } \\
\text { adjetivo e } \\
\text { pronome }\end{array}$ & $504 / 974$ & $51.7 \%$ & 0.454 \\
\hline & & & $\begin{array}{l}\text { Expressão } \\
\text { "se calhar" }\end{array}$ & $147 / 181$ & $81.2 \%$ & 0.702 \\
\hline
\end{tabular}

Esses resultados, por um lado, estão em consonância com o que é exposto em um estudo de Machado Soares (2002) sobre o PB. Segundo a autora, nomes substantivos ou adjetivos, influenciariam a concretização da variante $[\Lambda]$. Por outro lado, não está de acordo com o que foi encontrado em Brandão (2007), para quem os nomes, no PB, estariam favorecendo a ocorrência de [i $\mathrm{i}]$.

De qualquer forma, os resultados apresentados na tabela anteriormente parecem estar sendo influenciados pelo número de ocorrência de verbos nos corpora, uma vez que, no que diz respeito, por exemplo, à RMRJ, $74.8 \%$ das ocorrências de verbos estão sendo pronunciados com [li]. Em outras palavras, num conjunto de 886 ocorrências de / $/ /$ presentes em verbos, apenas 223 são concretizadas com a variante lateral palatal. Já no que diz respeito aos não verbos, observa-se que, de um total de 1169 dados, 466 itens são produzidos com [K]. Já na RMLIS, $66.6 \%$ das ocorrências de verbos estão sendo concretizados com a lateral palatalizada. Ou seja, num total de 431 ocorrências de $/ K /$ presentes em verbos, apenas 144 ocorrem com a manutenção da lateral palatal.

Tratando-se, em separado, a expressão "se calhar", percebe-se que, ainda que ela não ocorra no PB, no PE, ela é extremamente produtiva, com P. R. 0.702 (81.2\% dos dados). Nesse sentido, podem-se tecer dois comentários, a saber: (1) embora, aparentemente, tanto na RMRJ quanto na RMLIS os verbos pareçam ser a classe de palavras ideal para a ocorrência de [li], o grande número de vocábulos que figuram nessa classe pode estar interferindo no resultado; (2) como há uma maior concentração da variante [li] em se calhar, na RMLIS, supõe-se que essa expressão também possa estar influenciando a escolha desse fator como favorecedor da variação $[\Lambda] \sim\left[\mathrm{li}^{\mathrm{i}}\right]$. 


\section{CONSIDERAÇÕES FINAIS}

O estudo sobre o comportamento de / $/$ / na fala da RMRJ e na da RMLIS foi realizado, essencialmente, com o objetivo de aferir a atuação de variáveis estruturais e extralinguísticas sobre as variantes de $/ \mathcal{K} /$ registradas nos corpora representativos da fala da Região Metropolitana do Rio de Janeiro e da Região Metropolitana de Lisboa.

A pesquisa mostrou, de modo geral, que (1) em ambas as Regiões Metropolitanas a variante $[\mathrm{l}]$ é mais produtiva que $[K] ;(2)$ o fator linguístico selecionado como favorecedor da aplicação de [i] nas duas Regiões Metropolitanas parece sofrer interferência dos vocábulos com alta incidência nos corpora e (3) as demais variantes de $/ \mathcal{K} /([\mathrm{l}]$, [l], [j] e $\varnothing)$, pelo fato de as amostras retratarem a fala urbana, são pouco produtivas, incidindo em reduzido número de itens lexicais.

Assim, com base nos pressupostos da Teoria da Variação Laboviana, constatou-se, inicialmente, que, devido à sua baixa produtividade, as variantes despalatalização seguida de iode ([lij]), despalatalização ([1]), iodização ([j]), e síncope do segmento $(\varnothing)$ deveriam ser desconsideradas nas análises variacionistas que seriam realizadas com ambas as amostras.

Os resultados - que foram demonstrados de forma comparativa - revelaram que Faixa Etária e Classe do Vocábulo se configuraram favorecedoras para a realização de [li], não só na RMRJ como também na RMLIS.

Assim, atuaram em ambas as amostras:

(a) Faixa Etária - a variação [K] [li] é um fenômeno estável na RMRJ e na RMLIS, visto que os índices de ocorrência de [li] estão distribuídos de forma homogênea pelas três faixas etárias. Os resultados, no entanto, demonstram também que, embora os P. Rs. estejam próximos de .50, nas duas regiões em foco, o fato de, na RMRJ, os mais velhos estarem usando mais o $[K]$ e os mais novos, o [i $\mathrm{i}]$, sugere, de forma sutil, uma tendência crescente ao uso desta última variante no PB. Já no PE, o uso de [li] parece estar num processo mais avançado, já que a variante palatalizada está sendo mais usada pelos mais jovens e menos pelos mais velhos.

(b) Classe do vocábulo - Na RMRJ, os verbos se mostraram os favorecedores da lateral palatalizada. Já na RMLIS, os verbos e a expressão "se calhar" foram os fatores selecionados como os que mais favoreceriam a aplicação de [li]. No que toca a essa variável, a alta incidência de determinados vocábulos nas amostras pareceu influenciar a escolha de um fator em detrimento de outro. Como na RMRJ, há uma alta incidência de verbos na amostra, essa classe de palavras foi a selecionada como 
favorecedora de [li]. Na RMLIS, a escolha dos fatores favorecedores também foi induzida pela alta produtividade não só dos verbos como também do vocábulo calhar.

Como se observou ao longo da análise sociolinguística, os resultados encontrados quanto à variação $[\mathcal{K}] \sim[\mathrm{l}]$, provavelmente, não estão representando um condicionamento apenas estrutural/social, mas também um condicionamento determinado pela frequência alta de determinados vocábulos nas amostras.

\section{REFERÊNCIAS BIBLIOGRÁFICAS}

AGUILERA, Vanderci de A. O fonema [1h]: realizações fonéticas. Descrição e sua comprovação na fala popular paranaense. In: Encontro Nacional de Fonética e Fonologia, III. Anais. João Pessoa: UFPB, 1988.

BRANDÃO, Silvia Figueiredo. Sobre a lateral palatal no Português do Brasil. In: ASSIS, Rosa (org.). Estudo de Lingua Portuguesa (e de todas as linguas que fazem a nossa). Belém-PA: Unama, p. 63-86, 2006.

. Um estudo variacionista sobre a lateral palatal. Letras de Hoje. Porto Alegre, v. 42, n. 3, p. 89-99, 2007.

CRISTÓFARO-SILVA, Thaïs. Fonética e Fonologia do Português: roteiro de estudos e guia de exercícios. São Paulo: Contexto, 1999.

LABOV, William. Sociolinguistic Patterns. Philadelphia: University of Pennsylvania Press, p. 183-259, 1972.

. Padrões sociolinguísticos. Tradução de Marcos Bagno, Maria Marta Scherre e Caroline R. Cardoso. São Paulo: Parábola, 2008 [1972].

LUCCHESI, Dante. Sistema, mudança e linguagem: um percurso da Linguística neste século. Lisboa: Edições Colibri, 1998.

MACHADO SOARES, Eliane Pereira. Variações dos fonemas palatais lateral e nasal no falar de Marabá-PA. 2002. Dissertação (Mestrado em Linguística) - Universidade Federal do Pará, Belém, 2002.

MADUREIRA, Evelyne Dogliani. Reanálise de alguns aspectos da vocalização da lateral palatal no Português. Rev. Est. Ling, v. 8, n. 1, p. 125-145, Belo Horizonte, 1999.

MARTINS, Paula; CARBONE, Inês, PINTO, Alda; SILVA, Augusto; TEIXEIRA, António. European Portuguese MRI based speech production studies. Speech Communication. 50 (11-12), p. 925-952, 2008.

Articulatory Characteristics of European Portuguese Laterals: a 2D \& 3D MRI Study. In: Fala 2010, VI Jornadas en Tecnología del Habla and II Iberian SLTech Workshop, Vigo, 2010.

MELO, Gladstone Chaves de. A língua do Brasil. 4. ed. Rio de Janeiro: Padrão, 1981. 
NARO, Anthony Julius. Idade. In: MOLLICA, Maria Cecília (org.). Introdução à Sociolinguística Variacionista. Rio de Janeiro: UFRJ, 1992, p. 81-87.

PONTES, Eunice. Estrutura do verbo no Português coloquial. 2. ed. Petrópolis: Vozes, 1973.

QUANDT, Vivian de Oliveira. A lateral palatal no Português do Brasil e no Português Europeu. 2014. Tese (Doutorado em Língua Portuguesa) - Faculdade de Letras, UFRJ, Rio de Janeiro, 2014.

QUILIS, Antonio; FERNÁNDEZ, Joseph A. Curso de fonética y fonologia españolas: para Estudiantes angloamericanos. 4. ed. Madrid: Instituto Miguel de Cervantes, 1969.

SILVEIRA, Regina Célia Pagliuchi da. Estudos de fonologia portuguesa. São Paulo: Cortez, 1986. 
